\title{
Semi Automatic Pneumatic Gear box \& Lubrication System
}

\author{
Badadhe Aniket Sunil $^{1}$, Bhagat Omkar Vilas ${ }^{2}$, Chougule Siddharth Suresh ${ }^{3}$, \\ Chandrakant Dattatray Navale ${ }^{4}$, Prof. Shambhu Kumar ${ }^{5}$ \\ Student, Mechanical Department, Trinity Academy of Engineering ${ }^{1,2,3,4}$ \\ Guide, Mechanical Department, Trinity Academy of Engineering ${ }^{5}$
}

\begin{abstract}
In this paper a gear shifting mechanism is designed and applied to make the shifting process faster and slow destructible for the driver. The new device must be safe, with small dimensions, low construction and maintenance cost. This project tries to better gear shifting process by using tool as: a laboring four speed gear box, two pneumatic double acting cylinders, two pneumatic two position five ways directional control device valves, an electrical motor, a belt, two pulleys, limit switches, push buttons, bulbs, a table (holder) and power supply. According to suggested gear shifting mechanism the driver can select the transmission gear ratio without moving his hands from the steering wheel by putting the gear shifting push buttons on the steering wheel. By Using this mechanism leaves to the driver the excitement of choosing the shifting moment.
\end{abstract}

Keywords: About four key words or phrases in alphabetical order, separated by commas

\section{INTRODUCTION}

This paper describes in detail in an easy way to how to convert the traditional manually gear shifting mechanism to a semi-automated gear shifting mechanism. The development in this paper has concluded also the gearbox, which became much smoother and produces minimum noise. Gear shifting method must be simple to use and workable, these demands are much important especially for small cars used by special needs people. For some of the drivers, the gear shifting can cause some confusing at driving specially at critical situations. A crowded road on a hill or a sudden detour makes a lot of tension on the driver. One of the problem in this situation is to choose the right reduction ratio and engaging it at the right time. This design helps the driver to increase his focus on the road. Also minimizes the time needed to engage the required reduction ratio, which increases the vehicles' response.

This type of design may be considered as an educational model for gear shifting mechanism. so, we pointed to the following:

1. The suitable dimensions for the main components holder. So Keeping in mind the addition of other parts for enhancement and development.

2. A manual, 4-frontal speed gear box is used automobile drive is chosen for this design because it is easier to modify.

3. An electrical motor is used to create mechanical power instead of an internal combustion engine, which is difficult to be placed there. It is also used to make the engagement process effortless. Motor is variable speed ( 0 to $9000 \mathrm{rpm})$

4. A couple of pulleys and a belt are used to transmit power from the electrical motor to the gear box.

5. To avoid binding in the input shaft caused by the radial force, we used a bearing fixed on the holder.

6. We are using two pneumatic, double acting cylinders, per pair of gear shifting.

7. Two (five ways, two positions) directional control valves are used to change the compressed air direction. Every directional control valve has $230 \mathrm{~V}$ ac solenoid that converts electrical power to magnetic power, which attracts the spool inside the valve; this action changes the compressed air direction.

\section{CONSTRUCTION}

In this system there are two pneumatic cylinders consisting of pistons on either side of the vehicle pedal for engaging the gear. This cylinders are operated with the help of a pressurized air coming from compressor and it is controlled by a control unit (micro controller). The microcontroller is pre-programmed for working of the system. The role of the two pneumatic cylinders is one for increasing the gear speed and for decreasing the gear speed. For giving the forward motion, one cylinder is actuated \& for the reverse motion second cylinder is actuated. Instead of using clutch as in case of conventional Gear Shifting Mechanism, we are using Compressed Air. With the help of the compressed air, we actuate 


\section{International Advanced Research Journal in Science, Engineering and Technology}

Vol. 5, Issue 12, December 2018

double acting cylinder which in turn helps to shift the gears by using Direction Control Valve. The operation becomes quite simple and requires less time to operate. Driver does not need to away his hand from steering in order to operate the lever as in case of conventional gear shifting mechanism. The two solenoid valves are connected to the compressor with the help of hoses of $\varnothing 6 \mathrm{~mm}$ from which pressurized air is extracted. The solenoid valves are followed by two pneumatic cylinders with the help of air hoses. The cylinders are followed by a clutch pedal. Next to a clutch pedal gear box and a motor arrangement is present. The power to the control unit is supplied from the $12 \mathrm{~V}$ battery. When we pressed forward button, lever will change gear in forward direction, similarly when we apply reverse button gear will change in reverse direction.

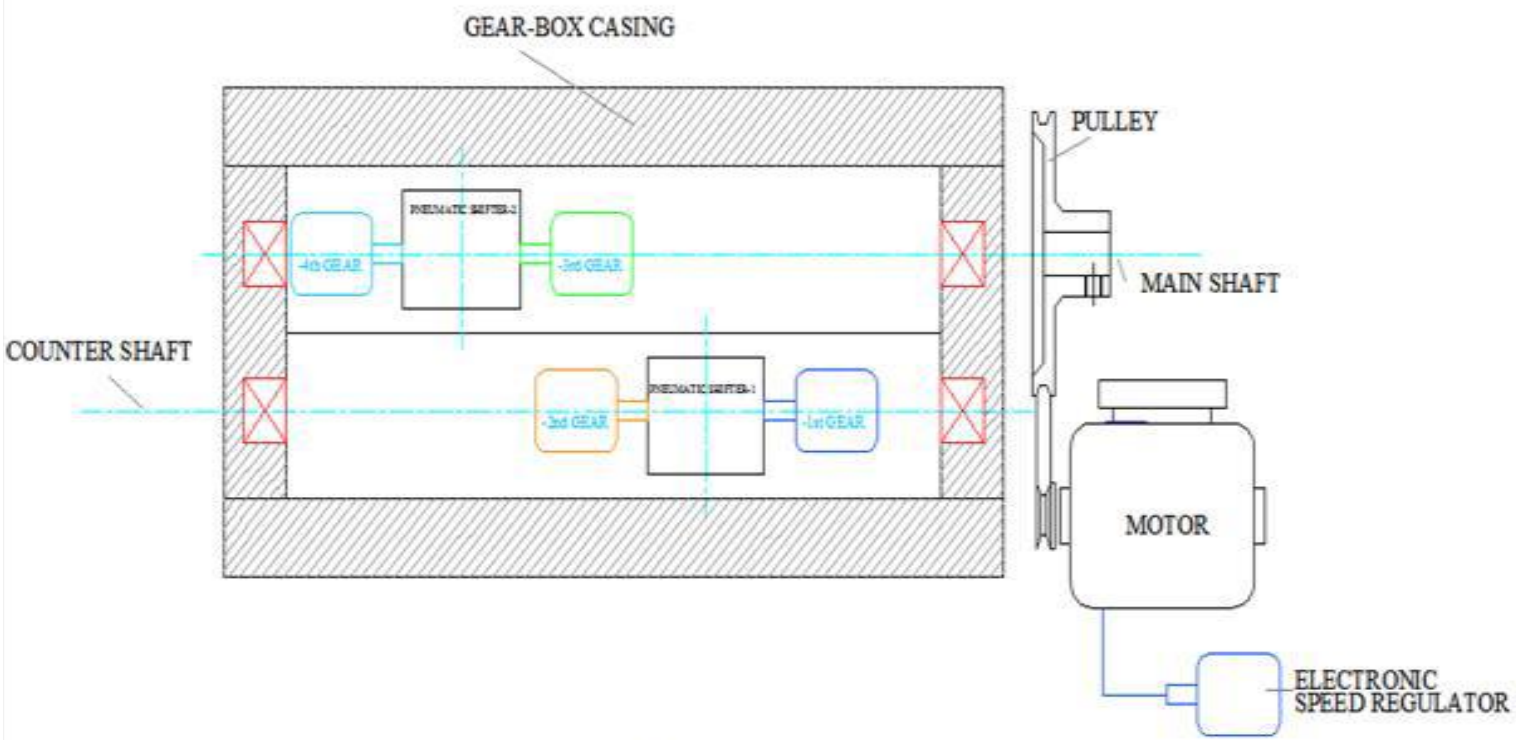

Figures: schematic layout of automatic gear box

\section{CALCULATIONS}

The torque necessary for the gear shifting is calculated as shown in the below calculation:

steps:

Data:

Diameter of piston, $=\mathrm{D} 1(\mathrm{~mm})$

Diameter of gear at lever, $=\mathrm{D} 2(\mathrm{~mm})$

Speed of the motor, $=\mathrm{N}(\mathrm{RPM})$

No. of teeth on smaller gear, $=\mathrm{t} 1$

No. of teeth on bigger gear, $=\mathrm{t} 2$

Power of motor, = P $(\mathrm{kW})$

Torque of driving gear $($ motor $)=\mathrm{T} 1(\mathrm{~N}-\mathrm{m})$ $=\mathrm{P} * 60 * 10^{\wedge} 3 / 2 * 3.15 * \mathrm{~N}$

Torque at driven gear $=\mathrm{T} 2(\mathrm{~N}-\mathrm{m})$

Gear ratio $=\mathrm{T} 2 / \mathrm{T} 1=\mathrm{t} 2 / \mathrm{t} 1$

Each part which involved in the gear shifting mechanism were designed initially with assumed dimensions and later modified with accurate measurements. Major components such as DC motor, gear pedal and chain are designed in CATIA V5 software and assembled offset in between the centre of DC motor and centre of gear.

Piston area $(\mathrm{A})=3.14 * \mathrm{D} 1^{\wedge} 2 / 4$

Connecting rod area $(\mathrm{a})=3.14 * \mathrm{~d} 11^{\wedge} 2 / 4$

Net area $\left(A^{\prime}\right)=A-a$

The extracted force,

The retracted force,

$\mathrm{FEX}=\mathrm{p}^{*} \mathrm{~A}$

$\mathrm{FRE}=\mathrm{P}^{*} \mathrm{~A}^{\prime}$ 


\title{
International Advanced Research Journal in Science, Engineering and Technology
}

\author{
Vol. 5, Issue 12, December 2018
}

\section{CONCLUSION}

The system eliminates the need of fuel, makes the environment pollution-free. The compressed air drives the air motor, which turn drives the vehicle's wheels. Once air is compressed, the air is stored in a tank. The compressed air is then used when the car needs a lot of energy, such as for starting up and acceleration. After achieving this desired gear shifting technology, we will able to get a smooth ride in all city conditions. We assume that there is an improvement in the fuel efficiency. This gear shifting technology will improvised the auto-clutch featured bike into automatic transmission vehicle. The complete gear changing mechanism is controlled by the acceleration of the bike. The vehicle then can be used in manual mode by switching off the power supply to the electrical components. The programmed embedded ' $\mathrm{C}$ ' codes, in the microcontroller, were modified and were the key source for changing gears in city limits as well as highways. Maintaining a proper pulse range, as in a program, or a constant speed of the vehicle resulted in better fuel efficiency. Fuel efficiency has been improved by $2 \mathrm{~km}$ upto $4 \mathrm{~km}$. After implementing the technology we have come to a conclusion that no human operation is necessary, other than accelerating, to ride the motor bike.

\section{REFERENCES}

[1]. Pneumatic Gear SystemTurpan's Gandhi1, Sagar Bhavsar2, Jay Shah3, Texas Solanki4, Jay I. Patel55Assistant Professor, Mechanical Department, Sigma Institute of Engineering, Vadodara, Gujarat, India.Published year-April-2017

[2]. A.A. Shingavi1, Tagad Sham Annasaheb2, Pagare Sagar Balasaheb3, Pawar Prashant Jayram4, Khose Satish Bhau5 "Electro-Pneumatic Gear Shifter”. IJSRD - International Journal for Scientific Research \& Development, Vol. 4, Issue 01, 2016.

[3]. S. Vijay Kumar1, P. Nithesh Reddy2, P. Masoom basha3 "Fabrication of pneumatic gear changer". IOSR Journal of Mechanical and Civil Engineering (IOSR-JMCE), Volume 11, Issue 3 Ver. V (May- Jun. 2014), PP 53-63.

[4]. Manaker N.A.1, Keshar S. D.2, Minded R.R.3, Khaja Abulafia A. H.4, Brahe S. E.5." Electro-pneumatic Gear Shifting Mechanism". International Research Journal of Engineering and Technology (IRJET), Volume: 03 Issue: 03, Mar2016. 